\title{
CIDADES VACINAM DOULAS E TERAPEUTAS CONTRA A COVID-19 ANTES DE IDOSOS E CASOS SÃO QUESTIONADOS PELO STF
}

\author{
CITIES VACCINATE DOULAS AND THERAPISTS AGAINST COVID-19 BEFORE ELDERLY \\ AND CASES ARE QUESTIONED BY THE SUPREME COURT
}

\author{
Andressa Cunha e Silva \\ Universidade Federal de Roraima, Boa Vista, RR, Brasil. E-mail: dedessinhacunha@gmail.com

\section{Danyele Beatriz Cavalcante de Oliveira} \\ Universidade Federal de Roraima, Boa Vista, RR, Brasil. E-mail: danybeatriz15@gmail.com
}

\section{Karen Santos da Silva}

Universidade Federal de Roraima, Boa Vista, RR, Brasil. E-mail: karensantos96188@gmail.com

\section{Douglas Verbicaro Soares}

Universidade Federal de Roraima, Boa Vista, RR, Brasil. E-mail: douglas_verbicaro@yahoo.com.br

DOI: https://doi.org/10.46550/amormundi.v2i4.109

Recebido em: 29.07.2021

Aceito em: 07.08.2021

Resumo: Este artigo analisará o episódio ocorrido durante o início da vacinação contra a Covid-19 quando doulas, terapeutas e outros profissionais que não atuam no combate ao vírus foram vacinados antes de idosos. Todos os esforços no sentido de promover uma discussão social no Brasil sobre a atual temática. Através do método dedutivo, pesquisas bibliográficas e sob uma perspectiva ética e moral, pode-se entender os reflexos da vacinação antecipada desses grupos. Nesse sentido, conclui-se que a falta de diretrizes claras para a vacinação acarretou uma série de problemas ao poder público e à sociedade em geral.

Palavras-chave: Pandemia. Solidariedade. Crise. Prioridades.

Abstract: This article will analyze the episode that occurred during the beginning of vaccination against Covid-19 when doulas, therapists and other professionals who do not work in the fight against the virus were vaccinated before the elderly. All efforts to promote a social discussion in Brazil on the current theme. Through the deductive method, bibliographic research and from an ethical and moral perspective, one can understand the reflexes of early vaccination of these groups. In this sense, it is concluded that the lack of clear guidelines for vaccination has caused several problems for the public authorities and society in general.

Keywords: Pandemic. Solidarity. Crisis. Priorities. 


\section{Introduçáo}

A população mundial vem sofrendo desde o início de 2020 em razáo da pandemia

Icausada pelo novo coronavírus (SARS-COV-2) e seus inúmeros problemas. A atuação do Brasil diante dessa crise mundial de saúde vem se mostrando pouco eficaz, tanto em relação à cooperação e solidariedade das pessoas, quanto nas medidas de combate às consequências da Covid-19 por parte do governo. Dentre os muitos fatores que impedem o Brasil de ter uma abordagem positiva, a principal parece estar na ausência de uma efetiva política nacional de enfrentamento à Covid-19, com políticas públicas unificadas pautadas em recomendaçóes cientificamente comprovadas.

No momento atual com várias vacinas sendo produzidas e aprovadas pelos países para o uso emergencial, ainda assim persiste um entrave, visto que não é possível vacinar a curto prazo a populaçáo inteira, pois náo há quantidades suficientes para a imunizaçáo de todos os cidadãos, além de ser necessário a segunda dose da vacina para melhor eficácia. Diante desse cenário, surgem questionamentos éticos e um deles é justamente pelo fato citado, de que nem todas as pessoas serão vacinadas imediatamente, a partir disso, é preciso vislumbrar quais são os critérios usados para priorizar determinados indivíduos, analisando qual seria a maneira mais justa de estabelecer tais diretrizes.

Uma imprecisão do Governo Federal em estabelecer quais profissionais de saúde deveriam ter prioridade para receber a vacina contra a Covid-19, na primeira fase da campanha de vacinação, permitiu que pessoas consideradas menos vulneráveis ao vírus fossem imunizadas antes dos grupos de maior risco. Foi o que ocorreu em certas cidades do país onde doulas, terapeutas, profissionais de educação física e outros foram vacinados antes de idosos e profissionais de saúde na linha de frente no combate ao Covid-19, grupos mais expostos à doença (JUCÁ, 2021)

A falta de clareza nas diretrizes chamou a atenção do Supremo Tribunal Federal, que determinou ao Ministério da Saúde que estabelecesse quem deveria ter prioridade na vacinação, tendo em vista a escassez de doses no início da campanha (JUCÁ, 2021)

A escassez de vacinas afetou até mesmo os grupos prioritários, por isso era necessário cautela e diretrizes claras definindo as pessoas que tinham prioridade na vacinaçáo. Diante disso, o Ministério da Saúde indicou aos Estados, por meio de ofício, a priorização dos trabalhadores envolvidos na campanha de vacinação e na assistência direta aos pacientes com covid-19. E após isso, os demais profissionais da saúde poderiam ser vacinados, ficando a critério dos estados e municípios qual seria a ordem a partir desse ponto.

Porém, muitos municípios estão incluindo na prioridade profissionais da saúde que não atendem diretamente pessoas com coronavírus. Nesse grupo foram vacinados profissionais de educação física, doulas, terapeutas, nutricionistas e psicólogos.

A Federação Nacional de Doulas (Fenadoulas) defendeu a inclusão do grupo na primeira fase de vacinação alegando que as doulas trabalham em "unidades de saúde diversas, hospitalares ou não, inclusive residências, independente da presença ou não de sintoma e de confirmação de contaminaçáo por covid-19区, além disso, trabalham diretamente com gestantes, que são inseridas nos grupos de risco (JUCÁ, 2021)

O caso desencadeou discussóes sobre as corriqueiras situaçóes de fura-filas da vacinação em todo o país. Além disso, algumas classes de profissionais ainda reivindicam o direito à prioridade 
na imunização contra a Covid-19, como secretarias de médicos, farmacêuticos, motoristas de ônibus e garis.

Ao mesmo tempo, está ocorrendo uma espécie de migração para outros estados em busca da vacina, o que prejudica não apenas o planejamento do município, como também as pessoas que têm o direito à vacina naquele local.

O objetivo do estudo será debater em torno de como foi definido a priorização das primeiras doses de vacinas que estão disponíveis, abordando as questôes que envolvem esse cenário caótico do Brasil, bem como os princípios éticos que devem ser considerados, na tentativa de alcançar alguma conclusão plausível para a situação em estudo.

Para a estrutura do estudo, se optou por levantamento bibliográfico e documental, com abordagem qualitativa em um método dedutivo. A investigação apresenta três seçóes: A primeira versa sobre o estabelecimento dos grupos prioritários para a vacinação. A segunda trata do questionamento do STF quanto à ausência da classificação dos grupos prioritários. A terceira seçáo aborda os princípios que devem ser considerados para determinar os grupos prioritários, seguidas das consideraçóes finais e referências.

\section{Como o Brasil estabeleceu os grupos prioritários}

A grande parte da desorganização na aplicação da vacina vem da falta de uma política pública unificada nacionalmente, como já foi mencionado. Isso quer dizer que, o Ministério da Saúde, ao estabelecer o Plano Nacional de Operacionalização da Vacina contra a Covid-19 contendo a ordem de vacinação para os grupos prioritários e os critérios necessários para a primeira fase de imunização das pessoas, não determina especificamente quais os profissionais de saúde deveriam ser primados para receber a vacina, além de permitir que os Estados e Municípios montassem seu próprio esquema de vacinação, segundo informaçóes contidas no site no Governo Federal.

Nesse contexto, recaiu sobre os Estados e Municípios decidir quais profissionais de saúde estariam na lista de prioridades, quadro que gerou muito conflito, já que consentiu as pessoas que não estavam na linha de frente do combate ao vírus fossem vacinadas antes dos indivíduos que possuem um alto risco de contaminação.

Segundo o Plano Nacional de Operacionalização (BRASIL, 2020, p. 9,12), as medidas presentes nele estáo de acordo com as orientaçôes da Organização Mundial da Saúde (OMS), são condicionadas às disponibilidades das vacinas aprovadas para o uso emergencial e provavelmente precisaram ser modificadas conforme as necessidades e o progresso da campanha de vacinação, além de que apresenta apenas diretrizes gerais, sendo suas especificaçốes e alteraçóes declaradas posteriormente por meio do Programa Nacional de Imunizantes. Entre os objetivos do Plano estão determinar as estratégias para a efetivaçáo da vacinação, anunciar a população-alvo e os grupos prioritários, potencializar os recursos disponíveis e equipar os Estados e Municípios para a vacinação.

Os critérios analisados para determinar os grupos prioritários partiu da reuniáo de dados sobre a detecção e a propagação do vírus, pois é indiscutível a habilidade de se propagar rapidamente pela população e de seus danos na saúde humana. Diante disso, foi feita uma comparação dos registros que envolviam os casos da doença, dos óbitos decorrentes dela e qual 
o perfil das pessoas que mais se tinham casos confirmados para o vírus.

Assim, constatou-se que o agravamento do quadro clínico e óbito dos indivíduos infectados com o vírus estava associado a características sociodemográficas, preexistência de comorbidades (insuficiência renal, doenças cardiovasculares, doenças pulmonares, diabetes, entre outras), idade superior a 60 anos e indivíduos transplantados de órgãos sólidos, além dos grupos de vulnerabilidade social e econômica (indígenas, populaçóes ribeirinhas, quilombolas, pessoas em situação de rua, refugiados e pessoas com deficiência residentes em abrigos, população privada de liberdade) com elevado grau de risco (BRASIL, 2020, p. 13,14,15)

Nesse sentido, os princípios que nortearam o Plano Nacional de Operacionalização são similares aos estabelecidos pela OMS. Foi decidido que a prioridade consistiria pela manutenção do funcionamento dos serviços de saúde, proteção dos indivíduos que possuem maior risco de desenvolver um quadro clínico grave ou até mesmo vir a óbito, proteção dos indivíduos com maior risco de infecção e a preservação do funcionamento dos serviços essenciais.

A partir disso, foi fixado a lista com os grupos prioritários para a vacinação, pessoas com 60 anos ou mais institucionalizadas, pessoas com deficiência institucionalizadas, povos indígenas vivendo em terras indígenas, trabalhadores de saúde (nesse grupo surgem críticas, visto que essa definição é compreendida como abrangente e por isso muitos profissionais da saúde que não estavam na linha de frente de combate ao coronavírus se aproveitaram para serem imunizados), pessoas com 75 anos ou mais; povos e comunidades tradicionais ribeirinhas, povos e comunidades tradicionais quilombolas, pessoas de 60 a 74 anos (BRASIL, 2020, p. 19-20), pessoas com comorbidades, pessoas com deficiência permanente grave, pessoas e situação de rua, população privada de liberdade, funcionários de sistema de privação de liberdade, trabalhadores da educação, entre outros grupos.

\section{Questionamento do STF quanto a ausência da classificação dos grupos prioritários}

Todo o exposto são informaçóes retiradas da segunda edição do Plano Nacional de Operacionalização da Vacina contra a Covid-19, onde foram elaboradas as diretrizes que guiaram os Estado e Municípios durante o período da vacinaçáo. No entanto, observou- se em todo o país que muitas pessoas que não deveriam estar incluídas no primeiro momento de imunização, ainda sim estavam sendo vacinadas. A partir disso, o Supremo Tribunal Federal (STF) determinou que o governo federal, divulgasse qual a ordem de preferência entre os grupos prioritários para a vacinação contra a Covid-19, uma vez que a imunização deveria ser definida com clareza e fundamentada em parâmetros técnico-científicos (BRASÍLIA, 2021).

A decisão do STF foi realizada nos autos da Arguição de Descumprimento de Preceito Fundamental (ADPF) 754, formulada pela Rede Sustentabilidade em que apresenta uma objeção sobre a atuação do governo federal em relação à imunização. $\mathrm{O}$ partido alega, que perante a carência das vacinas que estão à disposição, o Plano Nacional de Operacionalização é bastante impreciso. E com a falta de uma estrutura lógica e certa de preferências dentro de cada grupo prioritário, poderá gerar vários episódios de injustiça (BRASÍLIA, 2021). Por esse motivo a Rede pediu que fossem organizadas as preferências de cada classe dos grupos de risco e que essas especificaçóes fossem publicadas.

O Ministro Ricardo Lewandowski ao deferir o pedido explicou que a publicação dos 
critérios da vacinação e a ordem de preferência dentro de cada classe, está respaldada nos princípios da publicidade e da eficiência que regem a administração pública, no direito à informação, na responsabilidade da União de projetar e fomentar a defesa da sociedade contra as calamidades públicas, no dever do Estado de garantir a inviolabilidade do direito à vida, amparada na existência digna e no direito à saúde (BRASÍLIA, 2021).

O Ministro reconheceu que o Plano de Imunização indica quais os grupos prioritários e a quantidade de doses que serão necessárias, considerando os princípios da preservação do funcionamento dos serviços a saúde, a proteção dos indivíduos com maior risco de infecção e a preservação do funcionamento dos serviços essenciais. Porém faltou detalhar a ordem dentro de cada grupo prioritário, conforme o pedido da Rede. Disse ainda, que a discriminação das categorias compromete o dever da proteção a vida e a saúde (BRASÍLIA, 2021).

O ministério da saúde havia alertado que as primeiras etapas da campanha nacional de vacinação contra a Covid-19 não iriam atender $100 \%$ dos profissionais da saúde. O governo havia enviado para os Estados e Municípios que um dos focos seria atender 34\% dos trabalhadores da saúde, selecionando apenas aqueles que atuam diretamente na linha de frente contra a pandemia (PAULO, 2021).

Apesar do Plano Nacional de Imunização fazer uma recomendação na parte do texto chamada "Anexo I" em que o governo pede que seja feito o levantamento dos envolvidos na "resposta pandêmica" e que seja solicitado documento que comprove a "vinculação ativa" do profissional com o serviço de saúde, o anexo cria um equívoco, pois descreve uma lista extensa de trabalhadores de saúde aptos a receber a vacina (BRASIL, 2020, p. 71). Dentre esses trabalhadores estấo médicos, enfermeiros, nutricionistas, fisioterapeutas, além de profissionais da educação física, médicos veterinários, biólogos e profissionais que atuam em cuidados domiciliares como as doulas/parteiras, levando os profissionais que estão citados a acharem que estáo inclusos nos grupos que possuem o direito de serem imediatamente imunes, quando na verdade são apenas aqueles que estão na linha de frente do combate à pandemia.

O que dificulta ainda mais toda essa conjuntura é porque o Plano de Imunização só fala da primeira etapa das vacinaçôes, não estabeleceu as outras e ainda deixou que muitas dúvidas persistissem nessa primeira fase. No entanto, segundo o Ministério da Saúde (BRASIL, 2020, p. 71), na primeira fase de imunizaçáo estão pessoas com 60 anos ou mais institucionalizadas, pessoas com deficiência institucionalizadas, povos indígenas vivendo em terras indígenas, e trabalhadores da saúde, priorizando equipes de vacinação envolvidas na primeira etapa e trabalhadores de unidades vinculadas diretamente como referência para os casos suspeitos e confirmados de Covid-19.

\section{Princípios que devem ser considerados para determinar os grupos prioritários}

Nesse viés, busca-se compreender a relação entre a ética, o direito e os princípios, com o objetivo de ao menos conseguir apresentar como os princípios da saúde pública e da bioética mesmo náo sendo a melhor, ainda seria uma boa alternativa para determinar a preferência entre os grupos prioritários.

Para entender melhor a análise será abordado o conceito da ética:

Definida como um conjunto de valores morais e princípios que norteiam 
a conduta humana na sociedade. A ética serve para que haja um equilíbrio e bom funcionamento social, possibilitando que ninguém saia prejudicado. Nesse sentido, a ética, embora náo possa ser confundida com as leis, está relacionada com o sentimento de justiça social (RAMOS, 2020).

A partir da perspectiva da filosofia, a ética é uma ciência que estuda valores e princípios morais de uma sociedade. Diante dessa visão, é possível interpretar que no momento em que o indivíduo agisse conforme esses princípios e valores morais, a ética se tornaria a moral em realização, ou seja, a ética surgiria de um agir, de um comportamento que torna possível a correta convivência, pois o que é considerado certo pela sociedade estaria sendo colocado em prática (MELO, 2005).

No que concerne aos princípios Miguel Reale alude que:

Princípios são enunciaçôes normativas de valor genérico, que condicionam e orientam a compreensão do ordenamento jurídico, a aplicação e integração ou mesmo para a elaboração de novas normas. São verdades fundantes de um sistema de conhecimento, como tais admitidas, por serem evidentes ou por terem sido comprovadas, mas também por motivos de ordem prática de caráter operacional, isto é, como pressupostos exigidos pelas necessidades da pesquisa e da práxis (REALE, 2003, p. 37).

Nesses termos é possível concluir que o princípio é mais que uma simples regra, não apenas determina certas limitaçóes, mas também proporciona preceitos que fundamentam uma ciência e objetivam a sua correta compreensão e interpretação. O descumprimento de um princípio é mais grave do que o descumprimento de uma regra, considerando que viola não apenas um uma norma imperativa, mas a todo um sistema (CASTRO, 2012).

É com base nas definições acima e a importância que possuem na ordem pública, no bem estar coletivo e na justiça social, que o princípio do Sistema Único de saúde (SUS), previsto na Lei no 8.080/1990, art.70, inciso VII: "utilização da epidemiologia para o estabelecimento de prioridades, a alocação de recursos e a orientação programática”. (BRASIL, 1990) Além do princípio da justiça da bioética, que significa agir com equidade, isto é, oferecer mais a quem tem menos, que foi inspirado na teoria "justiça como equidade" de John Rawls, que fala sobre distribuição socialmente justa de bens em uma sociedade (RAWLS, 2002; DALL'AGNOL, 202).

No contexto atual a distribuição refere-se às vacinas, uma vez que se o objetivo é salvar mais vidas, os menos favorecidos que são as pessoas mais vulneráveis aos efeitos do vírus devem ser priorizadas e levando em conta que um desses grupos são os profissionais da saúde. É indiscutível que todos esses profissionais devem ser vacinados, porém nessa primeira fase que não se tem vacinas disponível para todos, era de suma importância restringir o grupo dos profissionais da saúde somente aqueles que estão na linha de frente, ficando os demais para as fases posteriores de vacinação. É importante entender a correta priorização para que o Plano de Imunização elaborado seja efetivo.

\section{Consideraçóes finais}

Diante do que foi abordado, é possível perceber que houve negligência por parte do Governo Federal, dos Estados, e Municípios. Pois foram inúmeros os erros que agravaram a situação caótica da pandemia, como a falta de informaçóes, esclarecimentos e organizaçôes, que 
corroborou para que alguns grupos prioritários tivessem sua imunização adiada, colocando suas vidas em risco. Esse cenário mostra como as autoridades públicas lidam com problemas sociais urgentes, principalmente no que diz respeito à saúde pública.

Contudo, revela também o comportamento egoísta e individualista da sociedade brasileira. Uma vez que, se vivemos em uma sociedade que por mais que não consiga, ao menos tenta zelar por um sistema que priorize determinados grupos sociais. Por exemplo, todo e qualquer atendimento ao público precisa atender primeiramente as prioridades, em transportes públicos os assentos são destinados preferencialmente às prioridades, que são as gestantes, idosos, pessoas com deficiência, obesos, pessoas com criança de colo e outros. Portanto, é evidente que em uma situação de calamidade na saúde pública, onde não se tem oferta abrangente e imediata de vacinas para todos, os grupos de risco devidamente estudados e classificados seriam preferência na vacinação. Mesmo assim, muitos profissionais da saúde não recusaram a imunização, ainda que cientes de que não era sua vez.

Nesse sentido, pode-se concluir que a sociedade brasileira passa não só por uma instabilidade na saúde pública, como também moral e ética. Pois, embora conscientes de que há legislação, princípios éticos e normas morais assegurando a preferência de determinados grupos, dependendo da situação vigente, esses fatores não foram suficientes para impedir a prática da conduta errada. Ademais, a reprovação moral social não surtiu nenhum efeito, pois casos dos profissionais de saúde não prioritários que receberam a vacina na primeira fase de imunização, foram bastantes comuns, sendo divulgados diversos eventos semelhantes na mídia em matérias que desaprovavam o ocorrido e mesmo assim se repetia. Mostrando que as pessoas muitas vezes possuem um discurso moral e/ou ético adequado para propagar o bem estar social, no entanto, na prática agem por conveniência, ignorando por completo as regras do bom convívio social (OLIVEIRA, 2021).

E tendo em vista que a quantidade de vacinas não atende a maioria da população brasileira, ou quiçá toda, pois há uma alta demanda e pouca oferta de vacinas. Além da falta de uma estrutura lógica e do quantitativo de vacinas necessárias aliada a falta de preferências dentro de cada grupo prioritário, há uma grande possibilidade de gerar vários episódios de injustiça hodiernamente (OLIVEIRA, 2021).

É nesse cenário que à luz do Direito percebemos que o direito à saúde está sendo violado. Apesar de ser direito de todos e estar firmado na nossa Carta Magna, não está sendo implementado imediatamente na prática, porque não há condiçôes reais para sua concretização em tempo hábil e útil devido a fatores diversos, como o supracitado: "fura filas", a falta de ética dos profissionais e de uma moral baseada em viver fraternalmente em uma sociedade visando à justiça.

Diante disto, ocorre o argumento da reserva do possível, a escassez patrimonial e a necessidade de parâmetros racionalizantes. Tal tese por vezes é utilizada pelo Estado por exemplo, para subtrair-se ao cumprimento de tais direitos. Apesar de os impedimentos para a concretude de uma efetiva campanha de vacinação contra à Covid-19 ser um fato à vista de todos, tal realidade não basta, para em contrapartida ser postulada à impossibilidade como motivo para isentar o Estado de cumprir direitos por ele mesmo assumidos como compromisso constitucional. E em especial faz-se recordar do compromisso com a dignidade da Pessoa Humana.

Podemos citar o art. $6^{\circ}$ da Constituição Federal que prevê o direito à saúde, como também o art. 196 da mesma lei, que enfatiza o caráter universal desse direito à ser garantido por meio de 
ações práticas de concretude, à saber:

Saúde é direito de todos e dever do Estado, garantido mediante políticas sociais e econômicas que visem à reduçáo do risco de doença e de outros agravos e ao acesso universal e igualitário às açóes e serviços para sua promoção, proteção e recuperação (BRASIL, 1988).

E citar ainda o art. 200 da CF, que trata das competências do Sistema Único de Saúde (SUS), sendo algumas delas: controlar e fiscalizar procedimentos, produtos e substâncias de interesse para a saúde e participar da produção de medicamentos, equipamentos, imunobiológicos, hemoderivados e outros insumos, executar as açôes de vigilância sanitária e epidemiológica e enfim. Com esse entendimento citamos que os princípios balizadores do SUS estão afirmados no art. $7^{\circ}$ da Lei $n^{\circ} 9.080 / 90$, em que temos: universalidade, integralidade da assistência, preservação da autonomia, igualdade da assistência à saúde, direito à informação, divulgação de informações quanto ao potencial dos serviços de saúde e a sua utilização pelo usuário, utilização de epidemiologia para o estabelecimento de prioridades, a alocaçáo de recursos e à orientação programática, entre outros.

Então, sob a ótica da Bioética aplicam-se tais princípios na área da saúde. Eles não decorrem apenas dos limites morais e legais, mas também de advindos das próprias normas específicas vigentes do SUS. E analisando a autonomia, reconhecida como um princípio clássico da Bioética, compreende-se que dentro da problemática deste artigo que no que tange aos envolvidos, carece-se de atitudes morais virtuosas, além do próprio cidadáo em pensar como integrante da sociedade - partindo da ética individual para uma coletiva. Aliás, o desafio iminente perante à grave crise de saúde pública seria agir com tal postura objetivando uma nação regida pelo princípio da justiça. $\mathrm{O}$ que demonstra o quão imperioso é valorizar a saúde e trazer condiçôes por meio de políticas públicas para tentar solucionar tais problemas e dilemas (VILLAS-BÔAS, 2014).

É necessário atenção em relação aos recursos sanitários em face de uma abordagem éticalegal. O desafio encontra-se em balizar por meio de elaboração e implantação de políticas que permitam e tornem viáveis à administração de recursos e bens disponíveis, de forma equânime e observada a reserva do possível real. Isto é, sem sacrificar o coletivo desmedidamente e nem os direitos fundamentais da pessoa, a ponto de colocar em risco a dignidade humana para promover um nível adequado de saúde sem ofender a dignidade e a cidadania e a naçáo como um todo. Sensibilizando as pessoas na necessidade de respeitar as ordens de lockdowns, assumir responsabilidade no cuidado individual, na relação profissional - paciente, um atendimento humanizado, respeitar as categorias prioritárias e tentar promover o bem comum.

Respeitando assim as escolhas compatíveis para o combate à epidemia de grupos prioritários. É fato que o reconhecimento que profissionais de saúde e os demais da linha de frente detém prioridade, bem como os grupos vulneráveis, como no caso dos idosos.Como mecanismo de equidade para promoção de segurança pública também. Também encontra outro desafio: manter um nível de proteção que permita justiça e equilíbrio entre as partes, sem invadir, de forma desmedida e irrazoável discriminatória, a esfera de decisão - autonomia. Com efeito, em beneficência mas em contrapartida, o problema está no fato de que o conceito ético e moral de bem não é objetivo e/ou unívoco. Afinal, quem seria capaz de afirmar com certeza o que é benéfico para o outro? O bem seria identificado com as medidas paliativas, à melhora, à cura, 
promoção da vida e da saúde, enfim aos atos regidos pelos princípios da beneficência.

Nesse diapasão, a falta de diretrizes claras alinhadas às garantias jurídicas sob à luz da bioética nos permite concluir que há uma insegurança na área da saúde estende-se à jurídica. Que são dilemas atrelados aos compromissos firmados em que pese à dignidade humana. Contudo, à falta de recursos, no caso vacinas para todos, as estratégias adotadas expóe a precariedade do Estado e demais órgãos envolvidos na missão de garantir o acesso de todas as pessoas residentes e domiciliadas no país ao cumprimento de suas garantias básicas de cidadania. Ou seja, não alcança de modo eficiente e os riscos evidentes - . Isto porque, como sabido, além de serem finitos os recursos, as dificuldades enfrentadas fogem do controle de Estado e afins, por ser uma questão de cunho moral e ético, de forma a iniciar no individual e findar no coletivo.

Destarte, citando John Rawls:

A distribuição natural dos bens não é justa ou injusta; nem é injusto que os homens nasçam em algumas condiçóes particulares dentro da sociedade. Estes são simplesmente fatos naturais. O que é justo ou injusto é o modo como as instituiçóes naturais tratam esses fatos (Rawls, 2002).

O que significa dizer, que à situação fática atual, por mais que se busque equilibrar para ambas as partes e exigir dos órgãos competentes o cumprimento haverá impasses e partes que saíram insatisfeitas. O que é o caso daqueles que tiveram a oportunidade de obter a vacina de forma antecipada. O que torna impreterível a obrigação de se buscar fazer o melhor, alocar e discutir com responsabilidade a matéria ao passo que se busque minorar os impasses e as consequências assumidas na tentativa de solucionar com zelo nas condutas e decisóes norteadas para tanto na ética. E para tanto é mister sopesar os interesses individuais e o coletivo, transcendendo as considerações morais. Primando não o ser, mas o dever-ser.

Em suma, não se trata de negar à força normativa das previsóes jurídicas ou dos princípios. Por mais que possamos discutir o certo ou errado. Necessitamos reconhecer que realmente (infelizmente) não há recurso para todos, e o sopesamento para escolher dentre os grupos as prioridades, é uma necessidade inegável, por ser considerado que esta é uma estratégia sanitária para conter o vírus.

\section{Referências}

BRASÍLIA. Vacinas: ministro determina que governo detalhe ordem de preferência em grupos prioritários. Supremo Tribunal Federal. Disponível em: <https://portal.stf.jus.br/noticias/ verNoticiaDetalhe.asp?idConteudo=460138\&ori=1>. Acesso em: 22 de jul. de 2021.

BRASIL. Ministério da Saúde. Plano Nacional de Operacionalização da Vacinação contra a Covid-19, 2020. Disponível em: <https://www.gov.br/saude/pt-br/media/pdf/2021/janeiro/25/ planovacinacaocovid_v2_25jan21.pdf>. Acesso em: 03 ago. 2021.

BRASIL. Decreto-lei no 8.080, 1990. Disponível em: <http://www.planalto.gov.br/ccivil_03/ leis/18080.htm>. Acesso em: 22 jul. 2021.

CASTRO, Carem Barbosa de. Teoria Geral dos Princípios. Rio Grande do Sul, set. 2012. Disponível em: <https://ambitojuridico.com.br/edicoes/revista-104/teoria-geral-dosprincipios/>. Acesso em: 22 jul. 2021. 
DALL'AGNOL, Darlei. Obrigação, Priorização e Distribuiçâo de Vacinas Contra a Covid-19: Reflexóes Bioéticas. UFSC/CNPq, p. 8-9-10-11, 2020.

JUCÁ, Beatriz. Sem diretriz clara, cidades vacinam doulas e terapeutas antes de idosos e casos vão parar na Justiça. EL País, São Paulo. Fev, 2021. Disponível em: <https://brasil.elpais.com/ brasil/2021-02-10/sem-diretriz-clara-cidades-vacinam-doulas-terapeutas-antes-de-idosos-ecasos-vao-parar-na-justica.html?ssm=whatsapp >. Acesso em: 23 de jul. 2021.

MELO. Osvaldo Ferreira de. Ética e Direito. Santa Catarina, set. 2005. Disponível em: <https://ambitojuridico.com.br/edicoes/revista-23/etica-e-direito/\#_ftnref15>. Acesso em: 22 jul. 2021.

REALE, Miguel. Liçôes Preliminares de Direito. 27a ed. São Paulo: Saraiva, 2003.

RAMOS, Jefferson Evandro Machado. Ética. São Paulo, ago. 2020. Disponível em: <https:// www.suapesquisa.com/o_que_e/etica_conceito.htm>. Acesso em 22 jul. 2021.

RAWLS, John. Uma teoria da justiça. Trad.Almiro Pisetta, Lenita Maria Rímoli Esteves. São Paulo, Martins Fontes, 2002.

PAULO, Paula Paiva. Ministério diz que "primeiras fases" da vacinação contra a Covid não Incluem todos os Profissionais da Saúde. fev. 2021. Disponível em: <https:/g1.globo.com/ bemestar/vacina/noticia/2021/02/08/ministerio-alerta-secretarios-de-saude-contra-a-alteracaode-grupos-prioritarios-na-vacinacao-contra-covid.ghtml>. Acesso em: 22 de jul. 2021.

OLIVEIRA, Joana. Os fura-filas da vacinação contra a covid-19 mostram a nefasta versão 2.0 do jeitinho brasileiro. El País. São Paulo, jan, 2021. Disponível em: <https://brasil.elpais. com/brasil/2021-01-30/os-fura-filas-da-vacinacao-contra-a-covid-19-a-nefasta-versao-20-dojeitinho-brasileiro.html>. Acesso em: 22 de jul. de 2021.

VILLAS-BÔAS, Maria Elisa. $O$ direito à saúde no Brasil: reflexôes bioéticas à luz do princípio de justiça. São Paulo: Ediçóes Loyola, 2014. 